\title{
Homens de Letras: intelectuais negros no Brasil imperial
}

Adilson Ednei Felipe ${ }^{1}$

Resumo: Homens e mulheres negros traçaram diversificadas estratégias de ascensão durante o século XIX, em pleno regime escravocrata. Dentre estas estratégias, cabe destacar o envolvimento com a produção gráfica - como autores ou editores. Este artigo visa a exposição de alguns representantes de uma elite intelectual negra e uma possível apreensão de alguns elementos que criaram condições para que tal grupo existisse.

Palavras-chave: negro, imprensa, intelectuais, livro, leitura, ascensão.

\begin{abstract}
Black men and women created diversified uplift strategies during the nineteenth century, in the slave regime. Among these strategies, it is worth mentioning the involvement with the graphic production - as authors or publishers. This article aims to expose some representatives of a black intellectual elite and a possible seizure of some elements that have created the conditions for such a group existed.
\end{abstract}

Keywords: blacks, press, intellectuals, book, reading, uplift.

\section{Leitura, identidade e cidadania}

O desenvolvimento das habilidades linguísticas possui, certamente, a capacidade de expandir a distinção existente entre aqueles que dominam a língua e aqueles que desconhecem os mecanismos para o seu devido manejo. Não há referência aqui à competência de falar, mas da lide com as complexidades da linguagem. Pierre Bourdieu em sua obra A Economia das Trocas Linguísticas, na qual pondera sobre temáticas relacionadas à linguística e sua relação simbólica no que concerne aos exercícios da sociabilidade, comenta sobre este desenvolvimento e a distinção propiciada pelo mesmo. Segundo Bourdieu, não é a capacidade de falar, "mas sim a competência necessária para falar a língua legítima que, por depender do patrimônio social, retraduz distinções sociais na lógica propriamente simbólica dos desvios diferenciais, ou numa palavra, da distinção"

1 Mestre pelo Programa de Pós-Graduação em História Social da Universidade de São Paulo. E-mail: edneifelipe@hotmail.com . 
(BOURDIEU, 2008, p. 42).

Certamente, o grupo social formado por negros, "mulatos", escravos e libertos, principalmente das regiões urbanas, também sentiu as transformações ocorridas, sendo possível, neste sentido, retomar as histórias de vida, destacando os aspectos que fazem relação à leitura e sua relevância nas relações sociais deste momento. Roger Chartier, em sua obra A Ordem dos Livros, embora realize um estudo voltado para o Antigo Regime, comporta reflexões relevantes para o presente opúsculo ao exaltar a importância da leitura no sentido em que "A leitura não é somente uma operação abstrata de intelecção; ela é engajamento do corpo, inscrição num espaço, relação consigo e com os outros"( CHARTIER, 1999, p. 16).

Condizente com o exposto, vale salientar o caso de Cruz e Sousa que, segundo Raimundo Magalhães Junior, apresentou ao, então, marechal Guilherme Xavier de Sousa alguns versos que compusera. O militar ficara impressionado, pois, "Rimar qualquer coisa, naqueles tempos, causava espanto e mesmo um herói nacional, como Osório, gostava de passar por poeta, escrevendo pachorrentamente seus sonetos, bem menos dignos de admiração do que os seus outros atos de bravura"( MAGALHÃES JÚNIOR, 1961, p. 13).

Pedro Pereira da Silva Costa afirma em sua biografia de Machado de Assis, que os pais, Francisco José de Assis e Maria Leopoldina Machado Câmara, eram tidos em alta estima por Maria José de Mendonça Barroso Pereira, dona da propriedade onde viviam como agregados pelo fato saberem ler. Realmente, ao menos em relação ao pai, tal informação é confirmada por Ayrton Marcondes: "Sobre ele consta que sabe ler e escrever e que assina o Almanaque Laemmert, publicado na corte anualmente entre 1844 e 1889'(MARCONDES, 2008, p. 41). Tal situação demonstra que a habilidade relacionada ao domínio da leitura e da escrita parecia permeado por uma espécie de prestígio vinculado a tal capacidade.

Novamente ressalta-se a inevitabilidade do contato e das relações que se entrelaçam desfigurando os traços originais da relação entre senhor e escravo ou deste com a sociedade, uma vez que este está inserido no cerne desta mesma sociedade por meio de atividades essenciais, assim como está inserido no conjunto de relações existentes entre pessoas pela convivência. A convivência diferencia-se, então, pelo desenvolvimento de habilidades que poucos privilegiados possuem, gerando oportunidade ao estabelecimento de novas relações sociais que, por sua vez, significam a possibilidade de ocupar outros espaços dentro das estratificações sociais. Sobre tais aspectos Florestan Fernandes elabora uma ponderação que interessa ao entendimento desta questão:

Muito se tem escrito sobre a importância do "negro de êxito" para modificar as atitudes, os estereótipos e os padrões de tolerância do 
branco. $\mathrm{Na}$ verdade, as pesquisas realizadas mostram que as presunções estabelecidas só são verdadeiras em um ponto. Quando se trata de "pessoas de cor" que aceitam os mecanismos de "exceção que confirma a regra". Esse mecanismo é inerente ao padrão tradicional de relação racial assimétrica e à ideologia racial dominante. Graças a ele a "pessoa de cor" é aceita como e enquanto indivíduo em função de um status fictício ou real, sem que os "brancos" que interagem com ela se obriguem a modificar suas atitudes mais íntimas a respeito do "negro" ou do "mulato". Quanto mais próxima estiver a "pessoa de cor" da sociedade tradicional brasileira, mais natural ela achará a existência de tal mecanismo e mais se valorizará, com as formas de aceitação ou infiltração na "sociedade" dele decorrentes (FERNANDES, 1972, p. 55).

A assimilação de tais mecanismos inclui, indiscutivelmente, o conhecimento da leitura e da escrita que, como afirmado, propiciará oportunidades outras de convivência. O destaque para esse conhecimento, provavelmente, atingira novas proporções com o advento do impresso no Brasil. O desenvolvimento do comércio voltado para a venda de impressos não tardou a ocorrer e se intensificar, principalmente durante a segunda metade do século XIX. Roger Chartier, embora não estivesse se referindo à situação específica do Brasil do referido período, traça considerações acerca da influência do desenvolvimento tipográfico nas relações sociais, políticas e econômicas.

Enquanto a simples posse do livro significou, durante tanto tempo, uma clivagem cultural, a conquista do impresso investiu progressivamente as posturas de leitura e os objetos tipográficos de uma tal função. As leituras distintas e os livros requintados se opõem, desde então, aos impressos prematuros e aos decifradores ineptos (CHARTIER, 1999, p. 22).

A presença do negro em círculos aos quais, supostamente, não deveria pertencer talvez viabilize uma reflexão em torno dos limites socioculturais impostos e a capacidade que algumas pessoas possuem para superá-los. Em O Som e a Fúria, Willian Faulkner realiza, por meio de uma de suas personagens, uma reflexão sobre a percepção do outro e a percepção de si mesmo aceitando o fato de que "a melhor maneira de considerar as pessoas, brancas ou negras, é considerá-las pelo que elas pensam que são, e depois deixá-las em paz” (FAULKNER, 1956, p. 75).

A ponderação da personagem de Faulkner indica, inegavelmente, o ato de perceber-se e ser percebido. Nesta ação contínua dentro do exercício de sociabilidade ocorre o desenvolvimento de elementos constitutivos da identidade de um indivíduo. Uma vez que ocorre a formação desta identidade através da combinação e da consolidação destes elementos, cuja definição e motivos para 
o surgimento independe, na maioria das vezes, da vontade do sujeito. De qualquer maneira, o indivíduo se apresenta e se representa, para si e para os demais, sob a forma em que é percebido, por si e pelos demais, como define Erving Goffman em A Representação do Eu na Vida Cotidiana.

A liberação de instalações tipográficas no Brasil, ou seja, o fim do monopólio da Typographia Nacional, desencadearia o surgimento de uma concorrência, ainda que restrita a alguns felizardos, estrangeiros em sua quase totalidade, principalmente franceses, na produção de impressos no Brasil, principalmente no Rio de Janeiro, onde se situava a corte. Em consonância com o incipiente contexto editorial também surgia um mercado de trabalho voltado para a impressão.

Inserido neste mercado está um homem negro, embora não seja o único, cujo nome seria mantido como um dos primeiros editores do Brasil a incentivar novas gerações de escritores brasileiros. Seu nome era Francisco de Paula Brito, pessoa afável que evitava conflitos políticos, criador da Sociedade Petalógica, amigo de D. Pedro II, com o qual fundaria a Typographia Dous de Dezembro, em referência ao fato de Paula Brito e o imperador D. Pedro II compartilharem a mesma data de aniversário, além de empresário audacioso.

Paula Brito adentrou no mercado editorial como aprendiz na Typographia Nacional, mas terminado o aprendizado rapidamente se empregou com o livreiro e impressor René Ogier. Passado o tempo torna-se compositor na equipe do jornal de Plancher, o Jornal do Commercio. Seu desenvolvimento intelectual acompanhou o seu desenvolvimento profissional expandindo a distância entre Paula Brito e a maioria de seus contemporâneos negros e brancos pobres. No jornal tornou-se chefe do departamento de impressão e, finalmente, diretor responsável. A inserção de Brito, um mestiço, no mercado livreiro não seria possível sem o desenvolvimento deste após a liberação concedida à existência de tipografias.

Devido à sua determinação em economizar e obter seu próprio prelo, Paula Brito consegue, em 1831, comprar o pequeno estabelecimento de seu parente Silvino José de Almeida Brito, permitindo ao seu espírito empreendedor, novos projetos envoltos em glórias relativas à produção gráfica. Importa aqui apontar os aspectos relativos à pluralidade no exercício da função de editor. Elizabeth Eisenstein descreve algumas características do ofício de mestre-impressor durante a Idade Moderna, citando a sua importância para o desenvolvimento da cultura letrada sob diversos aspectos:

$\mathrm{Na}$ qualidade de elemento-chave em torno do qual giravam todos os arranjos, o próprio mestre-impressor funcionava como ponte entre vários universos. Ele era responsável não só por conseguir dinheiro, como pelo 
suprimento de insumos e mão-de-obra, ao mesmo tempo [em] que tinha de desenvolver complexos esquemas de produção, lidar com greves, tentar avaliar as condições dos mercados livreiros e angariar o apoio de assistentes preparados. Tinha de manter-se em bons termos com as várias autoridades que asseguravam proteção e empregos lucrativos, sem se esquecer de cultivar e promover autores e artistas talentosos, que poderiam angariar lucros e prestígio à sua firma. Nas cidades em que sua empresa prosperava e ele pessoalmente atingia uma posição de influência junto aos seus concidadãos, sua loja tornava-se um verdadeiro centro cultural que atraía os literatos locais e personalidades famosas estrangeiras, ao constituir um local de reuniões e centro de mensagens para uma Comunidade do Saber cosmopolita e crescente (EISENSTEIN, 1998, p. 40).

As características apontadas por Elizabeth Eisenstein são condizentes com aspectos observados na atuação de Paula Brito como editor, pois além de supervisionar, incentivava novos autores, mantinha proximidade com os literatos do período, inclusive através de sua Sociedade Petalógica, e se responsabilizava pelos assuntos mercantis da produção editorial. O envolvimento de homens negros e "mulatos" na produção gráfica não se restringiu a Paula Brito, mas se estende às histórias de vida citadas e a serem elencadas novamente sob tal aspecto e além. José do Patrocínio iniciou suas atividades gráficas e literárias quando estudava para se tornar farmacêutico criando junto a seu companheiro, Dermeval da Fonseca, o jornal Os Ferrões assumindo os pseudônimos de, e declarando-se irmãos, Notus Ferrão (José do Patrocínio) e Eurus Ferrão (Dermeval da Fonseca). Esta condição declarada de irmandade não pode ser ignorada, pois, mesmo que não represente uma verdade incondicional, apresenta em alguma medida, a intensidade de convivência entre o mundo dos negros e o mundo dos brancos por meio das letras.

Não são tão escassos os exemplos de negros que obtiveram resultados, efetivamente, benéficos advindos do conhecimento da escrita e da leitura ou a produção gráfica envolvida. Ana Flávia Magalhães Pinto propõe, inclusive, o estabelecimento de laços de solidariedade entre os negros letrados. Ao mencionar a história de Francisco de Paula Brito, a autora realiza o seguinte comentário:

A partir do empenho de seu avô, um jovem de 22 anos adquire conhecimentos e recursos financeiros e, pouco depois, compra de seu primo as máquinas de uma tipografia. Desse momento em diante, impulsiona sua carreira, que envolverá nomes importantes das letras do país onde nascera, entre eles o autor do primeiro romance nacional e o maior literato daquele tempo, talvez de muitos outros. Esse poderia ser o enredo de uma narrativa ficcional qualquer, caso não tivesse tempo, espaço, dinâmica e, principalmente, personagens bem específicos. Viveram essa história homens negros livres que, na cidade do Rio de Janeiro da primeira metade do século 
XIX, estabeleceram laços de solidariedade entre si, base para o desenvolvimento de suas trajetórias pessoais: Martinho Pereira Brito, Francisco de Paula Brito, Silvino José de Almeida Brito, Antonio Gonçalves Teixeira e Souza e Joaquim Maria Machado de Assis (PINTO, 2010, p. 31).

A solidariedade também se apresentou na reivindicação do direito à alfabetização. Adriana Maria Paulo da Silva aponta a existência de uma escola no Rio de Janeiro que estaria destinada apenas a crianças negras ou pardas. O caso é interessante. Homens e mulheres negras produziram um abaixo-assinado exigindo a continuidade de atividades realizadas na escola do professor Pretextato Passos da Silva a fim de que seus filhos pudessem ser alfabetizados em uma escola onde não receberiam discriminação.

$\mathrm{O}$ ingresso e permanência das populações não brancas nas escolas brasileiras mobilizam importantes discussões e esforços há muitos anos. No tempo da escravidão, um grupo de pais de meninos "pretos pardos" residentes na cidade do Rio de Janeiro enfrentou o desafio de escolher um professor "preto", Pretextato do Passos e Silva, para seus filhos e de ajudálo a manter uma escola específica para eles (SILVA, 2010, p. 80).

Tais laços de solidariedade talvez fossem provenientes de uma identificação de classe conforme a concepção de E. P. Thompson que acredita que esta “... acontece quando alguns homens, como resultado de experiências comuns (herdadas ou partilhadas), sentem e articulam a identidade de seus interesses entre si, e contra outros homens cujos interesses diferem (e geralmente se opõe) dos seus"( THOMPSON, 2011, p. 10).

Há, também, a necessidade de lembrar a existência de casos em que mulheres negras conquistam seu espaço. O caso de Maria Firmina dos Reis deve ser ressaltado, pois, nascida no Maranhão, foi escritora e professora. Sua obra, Úrsula, ainda é referência quando se trata de produção literária abolicionista. Segundo Algemira de Macedo Mendes: “A primeira voz feminina no Brasil que registraria a temática do negro é a da maranhense Maria Firmina dos Reis, com a publicação do romance Úrsula, em 1859” (MENDES, 2011, p. 78).

Maurício José de Lafuente foi contemporâneo de Francisco de Paula Brito e , assim como este, dono de tipografia e frequentador da Sociedade Petalógica de Paula Brito, em outras palavras, outro homem negro envolvido com a produção gráfica. Segundo Ana Flávia Magalhães Pinto:

Entre os que lá circulavam [Sociedade Petalógica], encontrava-se Maurício José de Lafuente, outro "homem de cor". Figura singular neste contexto, antes de chegar ao Rio de Janeiro, Lafuente teria passado por várias províncias do Império - Espírito Santo, Bahia e Pernambuco -, constantemente envolvido em revoltas e disputas políticas (PINTO, 2010, p. $35)$. 
A autora menciona não só a participação ativa de Lafuente em contestações sobre a escravidão ou, ainda, sobre as discriminações sofridas por negros e "mulatos" livres, bem como a perseguição promovida pelas forças governamentais a este chegando a resultar em degredo. Além disso, esclarece não ter encontrado notícias sobre ocorridos durante seu afastamento, mas constata que, ao retornar, Lafuente retoma as atividades ligadas à produção gráfica (PINTO, 2010, p. 40).

Cruz e Sousa também se envolveria com as atividades editoriais ao chefiar a redação de um periódico intitulado $O$ Moleque que foi rechaçado pela sociedade local e, cujo título, associado à cor de seu redator-chefe, terminava por servir às zombarias e à depreciação por parte daqueles que desgostavam do poeta por conta da cor de sua pele ou por sua erudição, ou por ambos. Raimundo Magalhães Júnior disserta sobre a rejeição à iniciativa de Cruz e Sousa:

A reação à iniciativa foi tremenda. As prendadas e discretas senhoritas brancas, submetidas à disciplina dos lares burgueses da Província, não queriam ver seus nomes mencionados nas colunas de publicação de título picaresco, dirigida por um negro, filho de antigos escravos, que não conhecia o seu lugar. Isso seria motivo de grande irritação para os pais zelosos. "O Moleque" não era levado a sério. Não havia quem lhe dispensasse consideração alguma nos altos círculos que Cruz e Sousa tão desastradamente queria conquistar (MAGALHÃES JUNIOR, 1961, p. 41).

Não obstante, quando no Rio de Janeiro, o poeta chegou a trabalhar na redação de $A$ Cidade do Rio, não perdurou em tal ofício devido aos atritos com o dono do jornal, o "mulato", José do Patrocínio. Por sua vez, Machado de Assis, representante do estilo literário nomeado Realismo, que obteve ainda em vida o reconhecimento de suas obras e seu talento, trabalhou na oficina gráfica de outro negro, o empreendedor Francisco de Paula Brito. Apesar de, várias vezes, ser denunciado ao empresário sobre seu descuido com relação às obrigações do trabalho, por ficar lendo às escondidas, Paula Brito não o demitiu, pois simpatizava com os jovens que apreciavam a leitura (SILVA COSTA, 1974, p. 84).

Assim, Paula Brito incentivou os talentos artísticos do jovem rapaz, outro "mulato", para que este viesse a desenvolver seus romances publicando os dois primeiros romances de um Machado de Assis ainda inexperiente. Dessa maneira, este encontrou no mercado de trabalho editorial emprego e contato com a produção literária, sendo estes elementos fundamentais para seu desenvolvimento como escritor. Por exemplo, a relação entre os ímpetos empreendedores de Francisco de Paula Brito e o incentivo ao talentoso, mas desconhecido Machado de Assis, já descritos anteriormente, resultou nas duas primeiras publicações do escritor.

Nesse contexto, também, são traçadas relações de amizade, como é o caso de André 
Rebouças e José do Patrocínio que se empenham pela causa abolicionista e utilizam, para defender e divulgar seus ideais, não apenas espaço nos artigos publicados em periódicos como também os discursos inflamados em prol da nova ordem. A produção gráfica mais uma vez se mostra presente, neste aspecto, e abre espaço para o homem negro exercer sua reivindicação legítima, dentro de um contexto em que esta representa consumo e apropriação dos ideais defendidos. Em outras palavras, a venda de periódicos, publicação de versos, a inserção e aceitação do negro em diferentes círculos sociais propiciam, e ao mesmo tempo são propiciadas, pela, já citada, convivência.

Por intermédio dos jornais e revistas, palanques e assembleias, além de associações, os abolicionistas se informam, se conhecem, se identificam. Luiz Gama ganhou tristezas, mas também muito reconhecimento como defensor de escravos, mesmo não possuindo uma formação legitimada por meio de um certificado, um diploma. José do Patrocínio fazia de seu jornal, $A$ Cidade do Rio, um grande porta-voz da causa abolicionista. Sendo ainda, a Família Real simpática à causa, o abolicionismo também proporcionava uma aproximação com a elite. Os meios de comunicação impressos possuem grande relevância em um período no qual exerce predominância absoluta. Através de artigos publicados na Gazeta da Tarde e na Revista de Engenharia, outro homem negro defende o abolicionismo e adquire notoriedade na luta contra a escravidão: $o$ engenheiro André Rebouças.

Marcelo Bulhões comenta na introdução de sua obra Leituras do desejo: o erotismo no romance naturalista brasileiro sobre a hegemonia exercida pela literatura durante séculos relacionando o ato da leitura aos voos da imaginação e a um entretenimento solitário. O material gráfico, seja uma obra literária, seja um folhetim, era o material midiático predominante e a produção em vários níveis ocorreu propiciando ambiente próprio e diversificado de trabalho e apreciação. Dentro desta óptica o entendimento do material gráfico como principal instrumento na defesa do abolicionismo parece acertada.

Assim sendo, seja por meio da produção literária, da produção jornalística ou, mesmo, a produção gráfica, propriamente dita, negros e "mulatos" encontraram espaço e, em alguns casos, notoriedade, tornando a produção gráfica um ambiente no qual traçavam estratégias de ascensão social e econômica dentro de uma sociedade escravista, mas inseridos em um ambiente contaminado pela mentalidade abolicionista. Estes elementos, sociais, culturais e econômicos constituem o processo formativo destas pessoas que, estão, inextricavelmente, em uma relação de condicionamento e de relacionamento com o contexto histórico ao qual pertenceram. A sua presença em tal ambiente, tão fecundo nos espaços ocupados pela produção gráfica, tanto em seus aspectos 
pragmáticos - produção, comércio, cargos públicos -, quanto no imaginário - status, reconhecimento, sociabilidade -, contribui, incontestavelmente, para a formação da identidade destas pessoas.

O autor Alberto Manguel realiza comentários sobre Walt Whitman descrevendo brevemente alguns momentos da vida do poeta, traçando, inclusive, uma rápida menção às suas ocupações profissionais como auxiliar em um escritório de advocacia, tipógrafo e editor de jornal. Ressalta Alberto Manguel que "Whitman não ficou muito tempo no escritório de advocacia. Antes do fim do ano já era aprendiz de tipógrafo no Long Island Patriot, aprendendo a trabalhar com um prelo manual que ficava num porão apertado, sob a supervisão do editor do jornal e autor de todos os artigos" (MANGUEL, 1997, p. 194).

No Brasil do século XIX, a efervescência da produção gráfica, da venda de livros e da produção literária solicitava o emprego de mão-de-obra nas tipografias. Nesse clima, assim como Whitman, homens como Francisco de Paula Brito e Machado de Assis também iniciam suas carreiras relacionadas ao universo da escrita e da leitura como auxiliares de tipografia. A relação entre as personagens é, certamente, questionável visto que viveram situações muito distintas em termos de espaço geográfico e universo social. Entretanto, não é imperceptível a inserção no universo do trabalho e a relação com valores relacionados a este universo que são, essencialmente, burgueses. A referência aos valores burgueses não pretende ignorar a existência da burguesia enquanto classe proprietária, tampouco a história de sua consolidação econômica descrita por autores como Jacob Gorender, a Burguesia Brasileira ou Nelson Werneck Sodré, História da Burguesia Brasileira, ambos trabalhos importantes que consideram tanto os aspectos dos desenvolvimentos dos modos de produção e a consolidação dos grupos sociais, no caso classes, como ponderam sobre as peculiaridades do desenvolvimento capitalista no Brasil, como, por exemplo, Jacob Gorender que afirma partir do modo de produção escravista ao qual atribui uma determinação fundamental (GORENDER, 1981, p. 8).

Entretanto, ao tratar de valores, as definições procuradas adquirem outro foco, mais centradas em uma visão de mundo, uma formação de costumes que adentram no cotidiano da sociedade com a finalidade de compor uma percepção da realidade voltada ao entendimento de comportamentos e exercícios de sociabilidade, não pertencentes a um grupo específico, mas à sociedade como um todo - valores relacionados à ascensão por meio do talento e da dedicação, a participação ativa no ambiente social e político no qual está inserido, a ideia de uma família mononuclear etc. 
Neste sentido, cabe citar uma consideração realizada por Paulo Sérgio do Carmo, em relação ao trabalho, ao esforço individual, como meio de ultrapassar os limites impostos ao indivíduo: "Para muitos, o trabalho é a chave para superar os infortúnios e o parâmetro para medir a acumulação de capital, evidenciando a capacidade de 'vencer na vida'”(CARMO, 1992, p. 12). O trabalho é um dos elementos constitutivos da vida social das personagens que estão relacionadas a este universo, sejam os biografados ou outros negros de êxito. Muito embora seja necessário ressaltar a já descrita tendência ao ócio, disseminada por uma ideologia que relacionava o mundo do trabalho ao negro. Além disso, faz-se oportuno lembrar que a existência em um universo social permeado pela labuta diária e pela percepção desta labuta, se realizada de forma diligente, disciplinada, como meio para vencer obstáculos impostos pela cor e pelo nascimento corrobora para o desenvolvimento da ideologia em torno do trabalho citada por Paulo Sérgio do Carmo.

Florestan Fernandes em sua clássica obra A Integração do Negro na Sociedade de Classes comenta o fato de o negro não possuir as características culturais pertinentes em uma sociedade competitiva, tornando-se inapto a tal integração de forma plena, visto que este termina por herdar as características servis de comportamento e de percepção de sua realidade (FERNANDES, 1965, p. 388). Entretanto, em outro livro intitulado O Negro no Mundo dos Brancos o sociólogo assinala a participação intensa do negro e do "mulato" no ambiente de trabalho durante o período em que o escravismo predominou como modelo de relações trabalhistas.

No que tange ao passado, as regiões que possuíam vitalidade econômica podiam expandir a escravidão e, concomitantemente, as oportunidades de trabalho que eram conferidas ao negro e ao mulato, como libertos e homens livres. A estagnação econômica restringia a expansão da escravidão, mas não impedia, onde ocorresse, que o negro e o mulato participassem ativamente da estrutura ocupacional, como escravos, libertos e homens livres (FERNANDES, 1972, p. 46).

Esta intensa presença no mundo do trabalho como libertos ou livres ${ }^{2}$ incitavam a busca de possibilidades de ascensão. Logo a seguir, Florestan Fernandes reflete sobre a noção do "negro de êxito" e suas contrariedades. Dentro deste contexto explanatório tece a seguinte afirmação:

Todavia os negros e mulatos que estão verdadeiramente se incorporando à ordem social competitiva e que têm, com isso, possibilidades reais de mobilidade social ascendente na estrutura da sociedade de classes, tendem a repelir essas modalidades de acomodação. Não se contentam com as compensações oferecidas pelo convício com 'pessoas brancas de classe baixa' e não valorizam o branco por causa de sua cor. Assim lutam para

2 A diferença entre libertos e livres consiste na apreensão do liberto como aquele que foi escravo, mas que, de alguma forma, reconhecida juridicamente, conseguiu sua liberdade; enquanto entende-se por livre o negro que já nasceu sob tal condição. 
ficar em seu nível social, no 'meio negro' e na sociedade inclusiva (FERNANDES, 1972, p. 55.).

O objetivo das afirmações do autor não está direcionado à discussão sobre as possíveis contradições existentes em seu trabalho, no entanto, visam demonstrar as contrariedades da própria sociedade organizada política, social e economicamente. Estas contrariedades estavam presentes na sociedade de classes idealizada por Florestan Fernandes e estavam na sociedade monárquica em que existiram Machado de Assis, André Rebouças, Luiz Gama, José do Patrocínio, Francisco de Paula Brito, Cruz e Sousa, entre outros. Estas pessoas, com destaque para os biografados, ressaltando que não eram os únicos, encontraram nestas contrariedades, e na existência de um universo sociocultural, econômico e político que favoreciam e eram favorecidos pelos empreendimentos gráfico-literários, meios de existir e destacarem-se ocupando espaços e exercendo ofícios relacionados à imprensa.

\section{Ascensão}

Consta que um diplomata brasileiro de nome Magalhães de Azeredo solicitou, em mais de uma ocasião, a Machado de Assis, já então, prestigiado escritor, que intervisse por ele em seu projeto de publicação de um livro. Visto que, não raro, aqueles que desejassem ter suas obras publicadas, mais pelo prestígio entre colegas, admiradores e conhecedores da sublime arte da escrita, pois a vida de escritor não rendia pecuniários que valessem o esforço, tinham de pagar, o caríssimo Magalhães de Azeredo, que por esta época se encontrava no exterior, tentava reduzir, ou até mesmo, isentar-se do dispêndio.

Uma verdadeira epopeia tem início e, como se não bastasse, infrutífera. Infrutífera no sentido de que Magalhães de Azeredo, apesar das muitas correspondências trocadas com o amigo Machado de Assis e da assistência direta e contínua do prestigiado escritor no intento de auxiliar o caro diplomata, não conseguiu evitar o dispêndio. Segundo correspondência enviada por Magalhães de Azeredo, Lombaerts, editor frente ao qual Azeredo solicitava a intervenção de Machado de Assis, exigiu considerável soma para publicar a obra, estabelecendo, como opção ainda, condições restritivas com relação aos direitos do autor (LAJOLO; ZILBERMAN, 1996, p. 72).

De fato, os editores eram bastante reticentes com relação à publicação de autores desconhecidos. Alessandra El Far realça esse comportamento ao enfatizar que Baptiste Louis Garnier, um dos mais importantes editores do período, recusava-se a enviar para o prelo obras de autores que não tivessem, ainda, granjeado a estima do público leitor por meio de publicações em 
periódicos de seus contos ou artigos. As palavras da autora permitem o discernimento das dificuldades que se apresentavam aos escritores iniciantes.

Dizia-se na época que B. L. Garnier não publicava o primeiro livro de ninguém. Para conseguir o selo editorial de sua livraria, era preciso antes conquistar o apreço dos críticos literários, assinar colunas na grande imprensa ou ter algum destaque na vida política do país. Mesmo com tantos requisitos, Garnier tornou-se um dos editores mais importantes do século XIX. Publicou obra de José de Alencar, Machado de Assis, Joaquim Nabuco, Joaquim Manuel de Macedo, Graça Aranha, Olavo Bilac e Silvio Romero, dentre outros nomes do nosso cenário intelectual, recebendo, por isso, do Imperador D. Pedro II, o título de "livreiro e editor do Instituo Histórico e Geográfico" e uma comenda da Ordem da Rosa pelos serviços prestados às letras nacionais (EL FAR, 2006, p. 20).

Os casos exemplificados visavam demonstrar o quão árduo tinha sido o caminho trilhado por escritores dos mais variados estilos e procedências. No entanto, um diplomata como Magalhães de Azeredo não necessitava começar sua carreira de escritor nem tampouco prosseguir, caso viesse a mudar de ideia, no prelo como assistente. Neste caso, o pretendente à carreira contava com cargo de remuneração e prestígio considerável e, até mesmo, amigos influentes, como um Machado de Assis já no auge de sua carreira e notabilidade. Não foi esse o caso, entretanto, de nenhum dos autores negros citados até o momento. Não se trata de olvidar a influência de cidadãos, comerciantes e, até mesmo, editores benignos, que alicerçaram, até certo ponto, a formação e seu desenvolvimento literário, mas de esclarecer que nenhum destes pôde, simplesmente, usufruir de condições econômicas e relações sociais para a realização de tal empreendimento.

Tantas dificuldades e tantos apelos não existiriam sem um significado, um objetivo. É certo que escritores, poetas, jornalistas e mesmo editores passavam por vicissitudes financeiras e dificilmente poderiam sobreviver dos pecúlios advindos de suas publicações, isso quando conseguiam publicar. Marisa Lajolo e Regina Zilberman declaram que "Em muitos autores, fica difícil separar o papel de vítima das regras do sistema vigente do papel de conivente com elas, ao editarem e venderem livros por conta própria, renunciarem aos direitos autorais, aceitarem pagamentos simbólicos por sua produção" (LAJOLO; ZILBERMAN, 1996, p. 69). Porém, as dificuldades existentes para conseguir uma publicação, uma coluna em algum jornal, espaços tão concorridos entre os intelectuais, justificam, ao menos parcialmente, tais atitudes. Entretanto, não era apenas o sucesso literário que despertava o interesse dos possíveis autores, mas também, e talvez principalmente, as oportunidades empregatícias que acompanhavam o reconhecimento e as relações com pessoas influentes que poderiam indicá-los para cargos públicos. Para Myriam Fraga 
"A literatura era, então, uma espécie de abre-te Sésamo para a sociedade e para os poetas, tidos em alta conta, exibiam-se nos saraus, no intervalo das peças, nos teatros e até mesmo em reuniões políticas e sociais"( FRAGA, 2005, p. 31).

De fato, as disputas por espaços em que pudessem expor seu presumível talento eram frequentes entre os jovens candidatos a literatos. A biografia de Cruz e Sousa aponta tais situações vividas pelo poeta em sua terra natal, a pequena Desterro, quando aniversários, casamentos e elogios fúnebres eram momentos propícios para a exibição de talentos. Raimundo Magalhães Júnior expõe de forma bastante clara ao afirmar que o poeta de Desterro não deixava as oportunidades de demonstrar suas habilidades passarem.

O desejo de aparecer levava-o a aproveitar todas as oportunidades para declamar, em festas públicas, uma ou outra de suas produções. É a fase das poesias de circunstância, destinadas a celebrar aniversários, a homenagear alunos que terminaram os cursos, ou a chorar, como Malherbe, a morte de pessoas da terra. Nas festas cívicas, também não faltava com as suas rimas. Não era, aliás, o único do grupo, a proceder assim. Outros faziam a mesma coisa, aproveitando, ao máximo, as poucas oportunidades que tinham para aparecer e brilhar. Os nomes iam, depois, para os jornais, não raro com a transcrição da poesia, como quase infalível complemento do noticiário (MAGALHÃES JÚNIOR, 1961, p. 21).

Aparecer em jornais era, então, um meio de atingir a notoriedade, o reconhecimento do trabalho como poeta, escritor ou ambos. Mas o reconhecimento do público e dos meios literários representava, efetivamente, apenas uma parcela dos objetivos, pois, existia, também, o anseio por uma vida estável na qual pudessem manter a si e a família. Nestes casos, o reconhecimento literário e as amizades certas poderiam resultar em uma nomeação para um cargo público.

Inseridos no cotidiano do mercado de trabalho voltado para a produção gráfica, tanto brancos como negros e "mulatos", percebiam e reconheciam, dentro do processo de identificação com o meio, as possibilidades de ascensão social, através do reconhecimento pelo trabalho. Neste sentido, não seria implausível recordar que mesmo Varnhagen recorreu ao Imperador mais de uma vez para auxiliá-lo na edição do segundo volume de sua História Geral do Brasil, homenageando-o com um retrato na abertura do livro que o liberasse de pagar os direitos de importação (DELMAS, 2013, p. 41).

Tal estratagema não constituía novidade alguma, visto que desde o medievo a procura por aprovação, ajuda ou ambos, era caracterizada por homenagens a reis, santos, ou famílias ilustres. Esta prática se intensificaria com o desenvolvimento dos métodos de impressão e se estenderia até o século XIX. Sobre as dedicatórias como estratégia para conseguir proteção e 
financiamento, Ana Carolina Delmas afirma que:

No Brasil do século XIX, a prática de fazer dedicatórias estrategicamente destinadas a quem detinha o poder continuava sendo importante meio para os homens das letras, artes e ciências se sustentarem. A figura do letrado muito próxima do que se conhece atualmente como 'intelectual' - buscava valorizar seu espaço recorrendo a mecenas que lhes garantissem prestígio e proteção por meio de benesses e mercês (DELMAS, 2013, p. 41).

A autora aponta que as dedicatórias estiveram mais presentes durante o Período Joanino, embora tivessem se mantido por quase todo século XIX:

Ainda que de forma lenta e gradual e por seleto grupo, a prática das homenagens impressas se enraizou de tal forma que sua permanência pode ser percebida ao longo de quase todo o século XIX, trilhando um caminho próprio em sua manifestação tropical. A dinâmica da troca de favores por meio dos livros e do impresso no Brasil crescia em conjunto com o reino, e acompanharia os acontecimentos políticos do futuro Império (DELMAS, 2013, p. 43).

Francisco de Paula Brito, editor já citado, conseguiu sólida colaboração do imperador D. Pedro II, que se tornou acionista de sua gráfica. Laurence Hallewell explana com mais propriedade o ocorrido ao discorrer, primeiramente, o desenvolvimento incontestável dos negócios de Paula Brito que, em 1851, ingressou no campo da litografia e passou a publicar a revista A Marmota na Corte. No entanto, dois anos mais tarde viu-se compelido a aceitar uma sociedade com o imperador com o intuito de manter os negócios: "Essa ajuda foi-lhe prontamente concedida com base numa amizade pessoal iniciada com seu apoio a D. Pedro II dez anos antes e consolidada pela admiração do monarca por seu empenho em estimular os escritores brasileiros" (HALLEWELL, 2012, p. 172).

Certamente, incentivar a produção cultural e tecnológica parece ser uma característica marcante do governo brasileiro durante o Segundo Reinado. Marisa Lajolo e Regina Zilberman citam uma personagem de Orígenes Lessa da obra O Feijão e o Sonho para descrever a busca por estabilidade diante do reconhecimento como escritor e o cargo como servidor público (LAJOLO; ZILBERMAN, 1996, p. 69). Entretanto, as autoras advertem que, diante da conciliação entre produção literária e emprego público, é possível notar que:

Se o Estado não se responsabilizava pela alfabetização do público, nem preservava os interesses do país no mercado nacional, a nomeação de escritores para cargos públicos consistia, de um lado, na confissão de sua impotência institucional; de outro, na tentativa de remendar a impotência de forma canhestra, mutilando simultaneamente a instituição literária, por não reconhecê-la como tal, e o serviço público, no qual postulava a existência do ócio necessário à criação (LAJOLO; ZILBERMAN, 1996, p. 71). 
O funcionalismo público e o acesso a este era, indubitavelmente, de grande interesse para aqueles que buscavam projeção em suas produções literárias. Antônio Cândido exemplifica, no segundo volume de Formação da Literatura Brasileira, a ação de D. Pedro II, em relação ao empenho de Gonçalves de Magalhães no desenvolvimento da literatura nacional, na qual este é beneficiado como título de visconde em um momento em que seu prestígio literário começa a titubear: "Por isso mesmo o Imperador se apressou em dar-lhe outra, de visconde, 'com grandeza', para compensá-lo dos aborrecimentos literários..." (CÂNDIDO, 1975, p. 56).

O discreto Machado de Assis irá alcançar sua estabilidade financeira quando, finalmente, for nomeado Primeiro Oficial da Secretaria de Estado da Agricultura. Não faltava trabalho para um autor como Machado de Assis que possuía espaço garantido nos jornais para atuar com crônicas, críticas ou comentários, mas isso não era sinônimo de estabilidade, a qual pode ser assim considerada mediante a certeza de pagamento mensal. Com a saída do chefe do setor Rosendo Moniz por insubordinação, Machado de Assis ocupa o cargo e, posteriormente, em 1889, é promovido a diretor da Diretoria de Comércio da Secretaria de Estado e Agricultura, Comércio e Obras Públicas, cujo nome foi alterado com o advento da República, mas sem refletir de forma significativa nas funções atribuídas a Machado de Assis.

Convém, neste momento, refletir sobre a importância do funcionalismo público em casos como o de Cruz e Sousa, que não havia, como Machado de Assis, conquistado espaço que lhe fosse garantido nas publicações dos periódicos, pois ocupados pelos escritores consagrados. Apesar de não ter sido nomeado, biógrafos atentam para o fato, não comprovado devidamente, de que Cruz e Sousa teria sido convidado a assumir o cargo de promotor público em sua terra natal, mas não compareceu. Embora seja apenas uma especulação, o ocorrido não deixa de demonstrar a relação entre o reconhecimento da produção literária e a nomeação para cargos públicos.

Alexandro Dantas Trindade descortina em sua obra André Rebouças: um engenheiro do império que negros e mestiços abastados e educados não constituíam, por certo, uma raridade durante o Segundo Reinado, mas representavam, certamente, um fator constante de tensão (TRINDADE, 2011, p. 43). Em uma sociedade escravocrata, a admissão de homens negros e "mulatos" em certos círculos sociais seria impossibilitada. Entretanto, havia dois fatores que amenizavam e favoreciam o empreendimento de negros e "mulatos" livres: o movimento abolicionista e sua inserção, invariavelmente, no mundo do trabalho, ou seja, estava presente nas relações de sociabilidade nas quais buscava um espaço e, se possível, a ascensão social. As oportunidades, no entanto, eram indiretamente proporcionais aos empecilhos existentes na 
sociedade, na qual persistiam ideias, principalmente, em relação à inferioridade.

Propiciamente, coexistiram homens e mulheres, negros e "mulatos", inseridos em um contexto de expansão da indústria gráfica, de valorização da escrita e da leitura, de um governo monárquico, de um regime escravocrata e intensificação do pensamento abolicionista. Dentro deste universo sociocultural, formaram laços de solidariedade e delinearam estratégias de ascensão relacionadas à produção gráfica.

\section{Considerações finais}

É claro que se entende que as tipologias reflexivas, os questionamentos realizados na argumentação arrolada até o momento possuíram um intuito, mas as mesmas situações expostas e discutidas podem atender a propósitos outros, dependendo das intenções, da época, das relações com o mundo social e material em está inserido o pesquisador. Certamente, novos questionamentos podem ser feitos. Nessa esteira, cabe relembrar as considerações de Carlo Ginzburg acerca da imposição cultural a que pertence o indivíduo quando afirma que "Assim como a língua, a cultura oferece ao indivíduo um horizonte de possibilidades latentes - uma jaula flexível e invisível dentro da qual se exercita a liberdade condicionada de cada um" (GINZBURG, 2006, p. 20). Tal condição não deve, também, ser vista como um empecilho ao ofício do historiador, mas antes como um novo conjunto de possíveis apreensões.

Na obra organizada por Adauto Novaes, Tempo e História, um artigo, em particular, o de Nicole Loraux, chama a atenção por seu título: Elogio ao Anacronismo. No desenvolvimento argumentativo ocorre, evidentemente, uma defesa do anacronismo para que este seja percebido não como uma falha, um devaneio, mas sim como um conjunto de novos questionamentos sobre um período que, sendo objeto de estudo da historiografia, pertence ao passado.

A respeito do contexto social existente no período, com todas as suas variações, todas as diferentes concepções, sejam conflituosas, sincréticas ou apenas distintas umas das outras, não seria contrário salientar a coexistência geográfica de brancos e negros, não em uma condição de harmonia, evidentemente, mas, ainda assim, capaz de propiciar a existência de relações afetivas, estabelecendo, por sua vez, laços de solidariedade. Estes laços de solidariedade não eram bipolares, pois as relações se davam em diferentes esferas. Florestan Fernandes menciona a importância do auxílio fornecido por brancos aos denominados "negros de êxito" em sua obra O Negro na Sociedade de Classes, na qual trata da contextualização do início do século XX enquanto resgata 
informações e ponderações sobre o período anterior.

Os dados coligidos mostram que certos incentivos, que operavam no passado, ainda estão presentes. Assim, os dois incentivos que regulavam a ascensão social do negro e do mulato da ordem social tradicionalista - a influência socializadora da família branca e o paternalismo do branco continuam a ter eficácia. A inclusão transitória ou prolongada no seio de famílias brancas esclarece porque alguns "indivíduos de cor" apegaram-se, tenazmente, a ideais de personalidade-status e a aspirações sociais que entravam em choque quer com suas possibilidades socioeconômicas, quer com as tendências de ajustamento predominantes em seu meio social imediato. Em virtude de acidentes ligados às condições de seu nascimento, à dependência econômica da mãe ou da avó (empregadas de famílias importantes), à simpatia nascida da prestação de pequenos serviços, etc., um menor poderia ser incluído na periferia daquelas famílias e ficar exposto, de modo mais ou menos demorado aos influxos socalizadores de seu estilo de vida (FERNANDES, 1972, p. 136).

As afirmações de Florestan Fernandes são condizentes com as colocações anteriores e termina por alicerçar a argumentação sobre os processos de identificação já expostos nos casos de Cruz e Sousa, José do Patrocínio, Luiz Gama e Machado de Assis. Entretanto, como afirmado, tais auxílios seriam inócuos, ou sequer existiriam, não fosse a presença de espírito dos citados “indivíduos de cor”. O autor reconhece, pelo menos, a relevância desses esforços.

Em consequência [da situação exposta na citação anterior], passava a lutar denodadamente, por formas de autorrealização atípicas em seu meio social imediato. Propendia a avaliar a importância da instrução de modo realista e a associá-la, definidamente, a formas compensadoras de profissionalização (FERNANDES, 1972, p. 136).

Convém observar que, se por um lado, a ascendência pobre, justificaria a necessidade de auxílio advindo de famílias brancas, visto que o indivíduo em questão não conta com os recursos materiais nem mesmo dispõe de uma herança cultural, tal como já foi ressaltado por Pierre Bourdieu. Isto, contudo, não se aplica a André Rebouças que usufruía de tais condições propiciadas pela convivência em família abastada, bem relacionada e educada, que era sua e não a de outrem. Disso se presume que, as dificuldades enfrentadas e a necessidade de auxílio de pessoas influentes advêm de sua cútis e não de sua ascendência socioeconômica ou cultural imediatas. Não se deve olvidar que, apesar do auxílio de outros, Machado de Assis foi ajudado por Francisco de Paula Brito, que o incentivou e publicou seus escritos quando ainda era desconhecido. Esse tipógrafo entusiasta da cultura escrita que promoveu novos talentos como o do jovem Machado de Assis, era negro e não branco. Isso indica que havia uma composição de solidariedade também entre os negros 
e não apenas do branco para com o negro. Ademais, deve ser ressaltado que muitos dos cidadãos pobres eram brancos e tão ou mais ignorantes quanto qualquer cativo, com a diferença de que não estavam vinculados ao trabalho como escravos, isto é, cerceados de sua liberdade no sentido literal do termo.

Outro ponto interessante, a ser assinalado, seria a percepção de que a realidade do auxílio, da convivência e do jogo de influência está presente tanto entre brancos quanto entre negros. Se André Rebouças cogitava o desfavorecimento nos cargos, aos quais se candidatava, em função de sua cor de pele, isso significava que o engenheiro julgava que outros estavam sendo favorecidos, não por sua competência, mas pelas relações advindas do pertencimento a um grupo étnico privilegiado dentro das relações étnicas fundamentadas no preconceito e, consequentemente, na segregação de uns por outros.

Mantendo o enfoque, ainda, nas relações trabalhistas, seria interessante questionar, neste momento, sobre a percepção do negro enquanto força de trabalho. Buscar apreender o entendimento, a forma como o negro percebia a si mesmo neste sentido. Visto que, sendo a mão-deobra presente, de modo intenso, na sociedade de então, negros e "mulatos", cativos e livres, ocupariam, não apenas um espaço físico, mas também um espaço social, e no imaginário social, nos quais se entende como mão-de-obra, ou seja, como força produtora. Ana Flávia Magalhães resgata algumas destas percepções extraídas de periódicos do século XIX, direcionado a negros e "mulatos" e, não raro, produzido por estes. A autora expõe um excerto que vale reproduzir.

A classe de homens de cor, sem dúvida nenhuma, a mais numerosa e a mais industriosa do Brasil, parece atualmente voltada ao ostracismo pelos homens que nos governam, contra toda a justiça, contra a própria lei fundamental do país. Embora os particulares tratem-nos com as atenções merecidas, [...] todavia os fatos denunciam que o partido [conservador] que há tempos predomina na província parece manter o propósito desleal de ir apartando dos empregos públicos aqueles nossos que para eles haviam sido nomeados por consideração de seus talentos e virtudes, conforme preceitua a Constituição do Império. ${ }^{3}$

O excerto apresenta características de um discurso provindo de alguém que se percebe como responsável pelo desenvolvimento econômico nacional (mais industriosa do Brasil) e como cidadão (se pauta na Constituição). A identificação dos "homens de cor" não está limitada ao cativeiro, mas amplamente disseminada na sociedade representando força de trabalho e cidadania. No quadro referente aos biografados, pode-se notar a sua atuação no mercado de trabalho e, inclusive, talvez o

3 O Homem: Realidade Constitucional ou Dissolução Social, n. 1, p. 1 (apud PINTO, Ana Flávia Magalhães. Imprensa Negra no Brasil do Século XIX. São Paulo: Selo Negro, 2010, p. 56). 
mais importante para o presente estudo, suas atividades relacionadas à produção gráfica que os situava como força de trabalho, como cidadãos e como homens de letras.

De fato, as relações de solidariedade, os processos de identificação, o contexto político, social, cultural e econômico permitem a composição de interações identitárias e a confecção de estratégias ligadas ao cotidiano, isto é, relacionadas com o contexto em que existiram os biografados. Desta forma, embora tenham sido escolhidos alguns nomes para estudo, cuja explicação por tal opção consta já no início do presente opúsculo, está se tratando aqui de um aglomerado de estratagemas vinculados à existência cotidiana, à percepção de ser integrado ao mercado de trabalho, ao mesmo tempo em que se percebe desvinculado da sociedade setorialmente.

Embora tenham sido citados outros exemplos, ao explorar as informações dos biografados, é possível construir um enredo de lutas, agruras, alegrias, ascensão, ou não, ligados a um período escravocrata de inegável presença afro-brasileira constituída como mão- de-obra, criando processos de identificação coletivos e individuais relacionados com um material que sua cultura lhes pôs à disposição: a produção impressa. Considerando sua hegemonia midiática, da qual se torna resultante de uma valorização da cultura impressa, ou seja, o desenvolvimento das habilidades de leitura e escrita em um universo sociocultural em que, ainda, preponderavam os altos índices de analfabetismo.

Por meio desta, a produção impressa, cidadãos negros e "mulatos", pois assim se identificavam, chegaram a patamares de reconhecimento público e, até mesmo, governamental que distavam, e muito, de sua realidade inicial. Entretanto, tal empreitada não seria possível sem os citados processos de identificação com um universo social que os distava do indivíduo cativo, que os distava, inclusive, de brancos pobres e analfabetos, ou puerilmente alfabetizados, aproximandoos de grupos sociais mais intelectualizados, formados por brancos, negros e "mulatos" que cultivavam a erudição.

Ana Flávia Magalhães Pinto ao definir a situação dos "homens de cor", no século XIX, exercendo funções relativas à produção gráfica que "Ocuparam espaços decisivos para a expressão de suas opiniões sobre a sociedade em que viviam, estabeleceram alianças, romperam outras, enfrentaram dúvidas e, em alguma medida, tiveram sucesso em suas empreitadas" (PINTO, 2010, p. $31)$.

Embora os agentes sociais privilegiados no presente estudo representem um reconhecimento singular, suas histórias de vida contêm elementos comuns relativos a outros negros e "mulatos" com maior ou menor êxito em seus empreendimentos. Assim, como afirma Ana Flávia 
Magalhães Pinto, em alguma medida, outros tiveram triunfos a serem considerados. Visto que as biografias apresentadas não são o elo condutor, mas sim a produção impressa, elas cumprem com o objetivo de conciliar diferentes experiências de vida à propagação de uma visão de mundo permeada pela valorização da cultura escrita de forma que esta ocupe espaços determinados em sua realidade e em seu imaginário de maneira a representar possibilidades de ascensão vinculadas ao reconhecimento social e, quando possível, econômico.

Negros e "mulatos", dentro da realidade social em que existiram, conceberam formas de sobreviver e, em alguns casos, ascender, através dos meios que se lhe apresentavam. Dentre estes meios, estava, impreterivelmente, a produção impressa, fosse a produção literária ou a confecção de periódicos, ocupando, sem dúvida, um lugar de destaque. Ainda assim, havia a necessidade da inserção destes como agentes sociais, não apenas como membros adjacentes da vida comunal, mas a percepção de si mesmo como tais agentes. Em outras palavras, existe a necessidade de que estes indivíduos se identifiquem como citadinos, como pertencentes ao conjunto social. A partir deste reconhecimento de si mesmo como parte de um todo, assimilam os estratagemas sociais de convivência e de sobrevivência, forjam resistências, estabelecem vínculos e encontram possibilidades. A apreensão de tais possibilidades, ou de parte delas, permite a compreensão, mesmo que parcial, de um universo social específico, de um período em que a escravidão e a convivência com "indivíduos de cor" ocupando, ou lutando para ocupar, espaços privilegiados dentro da sociedade em que viviam coexistiram, conflituosos, de fato, em maior ou menor intensidade.

\section{Referências Bibliográficas}

ABREU, Márcia. Cultura Letrada: literatura e leitura. São Paulo: Unesp, 2006.

ALVES, Uelington Farias. José do Patrocínio: a imorredoura cor do bronze. Rio de Janeiro: Garamond, 2009.

AZEVEDO, Aluisio de. O mulato. São Paulo: Moderna, 1994.

BARRETO, Lima. Triste Fim de Policarpo Quaresma. São Paulo: Paulus, 2002.

BELO, André. História \& Livro e Leitura. Belo Horizonte: Autêntica, 2008.

BOCK, Ana Mercês Bahia; FURTADO, Odair; TEIXEIRA, Maria de Lourdes Trassi. Psicologias: uma introdução ao estudo de psicologia. São Paulo: Saraiva, 2002.

BOURDIEU, Pierre. A Distinção: crítica social do julgamento. São Paulo: Edusp; Porto Alegre, 
RS: Zouk, 2008a, p. 29.

BOURDIEU, Pierre. A Economia das Trocas Linguísticas: o que falar quer dizer. São Paulo: Edusp, 2008b.

BRAGANÇA, Aníbal; ABREU, Márcia. Impresso no Brasil: dois séculos de livros brasileiros. São Paulo: Edusp, 2010.

BRAUDEL, Fernand. Escritos sobre a História. São Paulo: Perspectiva, 1992.

BRAUDEL, Fernand. Reflexões sobre a História. São Paulo: Martins Fontes, 1992.

BULHÕES, Marcelo. Leituras do desejo: O Erotismo no Romance Naturalista Brasileiro. São Paulo: Edusp, 2003.

BURKE, Peter. Uma História Social do Conhecimento: de Gutenberg a Diderot. Rio de Janeiro: Zahar, 2003.

BURKE, Peter. A Escola dos Analles: a revolução francesa da historiografia. São Paulo: Unesp, 1992.

CÂNDIDO, Antônio. Formação da Literatura Brasileira: momentos decisivos. São Paulo: Edusp, 1975.

CARDOSO, Fernando Henrique. Capitalismo e Escravidão no Brasil Meridional: o negro na sociedade escravocrata no Rio Grande do Sul. Rio de Janeiro: Civilização Brasileira, 2003.

CARMO, Paulo Sérgio do. A Ideologia do Trabalho. São Paulo: Moderna, 1992.

CASTRO, Hileia Araújo de Castro. Esaú e Jacó ou Luiz Gama e André Rebouças: um estudo sobre a negritude no Brasil Imperial.1999. x f. Dissertação (Mestrado em História Social). Unidade FFLCH, Universidade de São Paulo, São Paulo,1999.

CHARTIER, Roger. A História Cultural: entre práticas e representações. Rio de Janeiro: Bertrand Brasil, 1990.

CHARTIER, Roger. A Ordem dos Livros: leitores, autores e bibliotecas na Europa entre os séculos XIV e XVIII. Brasília: UNB, 1994.

CHARTIER, Roger. Práticas da Leitura. São Paulo: Estação Liberdade, 2011.

COSTA, Emília Viotti da. A Abolição. São Paulo: Global, 1997.

COSTA, Emília Viotti da. Da Senzala à Colônia. São Paulo: Unesp, 2010.

COUTINHO, Afrânio; SOUSA, J. Galante de (Dir.). Enciclopédia de Literatura Brasileira. São Paulo: Global, 2001.

DARNTON, Robert. O Beijo de Lamourette: mídia, cultura e revolução. São Paulo: Companhia das 
Letras, 1990.

DARNTON, Robert. O Grande Massacre de Gatos: e outros episódios da história cultural francesa. São Paulo: Paz e Terra, 2014.

ECO, Umberto. Seis Passeios pelos Bosques da Ficção. São Paulo: Companhia das Letras, 1994.

EISENSTEIN, Elizabeth L. A Revolução da Cultura Impressa: os primórdios da Europa moderna. São Paulo: Ática, 1998.

EL FAR, Alessandra. O Livro e a Leitura no Brasil. Rio de Janeiro: Jorge Zahar, 2006.

FAORO, Raymundo. Machado de Assis: a pirâmide e o trapézio. São Paulo: Globo, 2001.

FAULKNER, William. O Som e a Fúria. São Paulo: Círculo do Livro, 1956.

FERNANDES, Florestan. A Integração do Negro na Sociedade de Classes. São Paulo: Dominus, 1965.

FERNANDES, Florestan. O Negro no Mundo dos Brancos. São Paulo: Difusão Europeia, 1972.

FERREIRA, Marieta de Moraes; AMADO, Janaína. Usos e Abusos da História Oral. São Paulo: FGV, 1996.

FERRO, Marc. A História Vigiada. São Paulo: Martins Fontes, 1989.

FOUCAULT, Michel. Microfisica do Poder. Rio de Janeiro: Edições Graal, 1979.

FRAGA, Myriam. Luiz Gama. São Paulo: Callis, 2005.

FRANCO, Maria Sylvia de Carvalho. Homens Livres na Ordem Escravocrata. São Paulo: Kairós, 1983.

FREYRE, Gilberto. Casa Grande e Senzala. Rio de Janeiro: Record, 1989.

GEERTZ, Clifford. A interpretação das Culturas. Rio de Janeiro: Zahar, 1978.

GINZBURG, Carlo. O Queijo e os Vermes: o cotidiano e as ideias de um moleiro perseguido pela inquisição. São Paulo: Companhia das Letras, 2006.

GOFFMAN, Erving. A Representação do Eu na Vida Cotidiana. Rio de Janeiro: Vozes, 1975.

GORENDER, Jacob. A Burguesia Brasileira. São Paulo: Brasiliense, 1981.

GUILHON, Orlando J. F. José do Patrocínio. Rio de Janeiro: Três, 1974.

HALLEWELL, Lawrence. O Livro no Brasil: sua história. São Paulo: Edusp, 2012.

LAJOLO, Marisa; ZILBERMAN, Regina. A Formação da Leitura no Brasil. São Paulo: Ática, 1996.

LAJOLO, Marisa; ZILBERMAN, Regina. A Leitura Rarefeita: leitura e livro no Brasil. São Paulo: Ática, 2002.

LEMINSKI, Paulo. Cruz e Sousa: o negro branco. São Paulo: Brasiliense, 2003. 
LIBBY, Douglas Cole; PAIVA, Eduardo França. A Escravidão no Brasil: relações sociais, acordos e conflitos. São Paulo: Moderna, 2005.

LORAUX, Nicole. Elogio ao Anacronismo. In: NOVAES, Adauto (org.). Tempo e História. São Paulo: Companhia das Letras, 1992.

MAgAlHÃeS JUNIOR, Raimundo. Poesia e Vida de Cruz e Souza. São Paulo: Das Américas, 1961.

MANGUEL, Alberto. Uma História da Leitura. São Paulo: Companhia das Letras, 1997.

MARCONDES, Ayrton. Machado de Assis: exercício de admiração. São Paulo: A Girafa, 2008.

MARINHO de AZEVEDO, Celia Maria. Onda Negra, Medo Branco: o negro no imaginário das elites do século XIX. São Paulo: Annablume, 2004.

NABUCO, Joaquim. O Abolicionismo. Rio de Janeiro: Nova Fronteira, 2000.

NETO, Godofredo de Oliveira. Cruz e Sousa. Rio de Janeiro: Garamond, 2010.

NIZZA DA SILVA, Maria Beatriz. A Primeira Gazeta da Bahia: Idade D’Ouro do Brasil. São Paulo: Cultrix, 1978.

NOVAES, Adauto (org.). Tempo e História. São Paulo: Companhia das Letras, 1992.

ORICO, Osvaldo. O Tigre da Abolição. Rio de Janeiro: Civilização Brasileira, 1977.

PEIRCE, Charles Sanders. Semiótica. São Paulo: Perspectiva, 2005.

PINTO, Ana Flávia Magalhães. Imprensa Negra no Brasil do Século XIX. São Paulo: Selo Negro, 2010.

PRADO JÚNIOR, Caio. Formação do Brasil Contemporâneo. São Paulo: Brasiliense, 1971.

REIS, João José; GOMES, Flávio dos Santos (Orgs.). Liberdade Por Um Fio: Histórias dos quilombos no Brasil. São Paulo: Companhia das Letras, 1996.

SCHWARCZ, Lilia Moritz. Retrato em Branco e Negro: jornais, escravos e cidadãos em São Paulo no final do século XIX. São Paulo: Companhia das Letras, 1987.

SCHWARZ, Roberto. Ao Vencedor as Batatas: forma literária e processo social nos inícios do romance brasileiro. São Paulo: Editora 34, 2012.

SEMERANO, Cláudia Marino; AYROSA, Christiane. História da Tipografia no Brasil. São Paulo: MASP, 1979.

SEVCENKO, Nicolau. Literatura como Missão: tensões sociais e criação cultural na Primeira República. São Paulo: Companhia das Letras, 2003.

SILVA, Eduardo; REIS, João José. Negociação e Conflito: a resistência negra no Brasil escravista. São Paulo: Companhia das Letras, 1989. 
SILVA, Lutero Rodrigues da. Carlos Gomes, um Tema em Questão: a ótica modernista e a visão de Mario de Andrade. USP: Tese de Doutorado, 2009.

SILVA COSTA, Pedro Pereira da Silva. Machado de Assis. São Paulo: Três, 1974.

SODRÉ, Nelson Werneck. História da Burguesia Brasileira. Rio de Janeiro: Civilização Brasileira, 1964.

SODRÉ, Nelson Werneck. História da Literatura Brasileira. Rio de Janeiro: Civilização Brasileira, 1969.

SODRÉ, Nelson Werneck. História da Imprensa no Brasil. Rio de Janeiro: Graal, 1977.

THOMPSON, E. P. A Formação da Classe Operária Inglesa: a árvore da liberdade. São Paulo: Paz e Terra, 2011.

TODOROV, Tzvetan. A Conquista da América: a questão do outro. São Paulo: Martins Fontes, 2003.

TREVISAN, Leonardo. Abolição: um suave jogo político? São Paulo: Moderna, 1988.

TRINDADE, Alexandro Dantas. André Rebouças: um engenheiro do Império. São Paulo: Hucitec, 2011.

\section{Periódicos}

DELMAS, Ana Carolina. Os Bajuladores da Majestade. Revista de História da Biblioteca Nacional. Rio de Janeiro, ano 8, n. 93, junho de 2013, p. 40-43.

FARIA, Sheila de Castro. Sinhás Pretas. Revista de História da Biblioteca Nacional. Rio de Janeiro, ano 7, n. 78, março de 2012, p. 26-29.

MATTOS, Hebe Maria. A Face Negra da Abolição. Nossa História. São Paulo, ano 2, n.19, maio de 2005, p. 16-20.

SILVA, Adriana Maria Paulo da. Uma Escola Diferente. Revista de História da Biblioteca Nacional. Rio de Janeiro, ano 5, n. 55, abril de 2010, p. 80-83.

\section{Referências eletrônicas}

BARRETO, Lima. Recordações do Escrivão Isaías Caminha. São Paulo: Ática, 1995. Disponível em: <http://www.dominiopublico.gov.br/download/texto/bv000157.pdf. $>$ Acesso em: 8 mar. 2015.

MACEDO, Concessa Vaz de. A Indústria Têxtil, suas Trabalhadoras e os Censos da População de Minas Gerais do Século XIX. Varia História, v. 22, n.35, Belo Horizonte, jan/jun 2006. 
Disponível $\quad$ em: $\quad<\underline{\text { http://www.scielo.br/scielo.php?pid=S0104- }}$ $\underline{87752006000100012 \& \text { script }=\text { sci arttext }}>$ Acesso em: 8 mar. 2015.

MENDES, Algemira de Macedo. O Discurso Antiescravagista em Úrsula, de Maria Firmina dos Reis. Cerrados, Brasília, v. 20, n. 31, 2011, p. 78. Disponível em: $<$ http://periodicos.unb.br/index.php/cerrados/issue/view/793. $>$ Acesso em: 8 mar. 2015.

MORAES, Renata Figueiredo. Uma Pena de Ouro para a Abolição: a lei do 13 de maio e a participação popular. Revista Brasileira de História. São Paulo, v. 33, n. 66, jul/dez 2013,

p. 49-69. ISSN 1806-9347. Disponível em: < http://www.scielo.br/pdf/rbh/v33n66/a04v33n66.pdf.> Acesso em: 12 jan. 2015.

TOMASEVICIUS FILHO, Eduardo. O Emprego de Mão-de-Obra Escrava em Atividades Industriais no Brasil - século XIX. Revista de Economia Política e História Econômica. São Paulo, n. 26, ano 8, agosto de 2011, p. 45-61. ISSN 1807-2674. Disponível em: <http://www.excedente.org/wp-content/uploads/2014/11/REPHE26.pdf.> Acesso em: 8 mar. 2015.

Recebido em 12/05/16 - Aprovado em 30/06/16 